\title{
Left behind
}

A review of therapist and process variables influencing dropout from individual psychotherapy

Johanna Roos

Handledare Andrzej Werbart

PSYKOTERAPEUTEXAMENSUPPSATS

PSYKOTERAPEUTPROGRAMMET, T6, VT 2011

STOCKHOLMS UNIVERSITET

PSYKOLOGISKA INSTITUTIONEN 


\title{
Left behind
}

\author{
A review of therapist and process variables \\ influencing dropout from individual psychotherapy
}

\author{
Johanna Roos
}

\begin{abstract}
Dropping out from psychotherapy is a complex phenomenon that has impact on the mental health of the dropout patients primarily and the mental health care secondarily and needs to be understood from many different angles. Among potential predictors, patient variables are so far most thoroughly examined. This tends to simplify the causal explanations that may result in adjustment of treatment procedures that are inadequate for addressing the problem. The aim of this review is to examine the current state of knowledge about therapist and process factors influencing dropout from individual psychotherapy. After electronic searches in databases 40 relevant studies published 20002011 were identified. The results show that the therapist skills and degree of education and experience has a great impact on dropout rates, psychotherapeutic progress and outcome, and the quality of alliance and relationship. The conclusions are that the therapists need training, peer and organisational support for accomplishment and enhancement.
\end{abstract}

Dropout or premature termination of psychotherapy is an important clinical phenomenon. The frequencies for dropouts vary strongly among studies with frequencies between 30-50 \% (Baekeland \& Lundwall, 1975; Barrett et al. 2008; Chiesa, Wright \& Neeld, 2003; Kazdin \& Mazurick, 1994; McMuran, Huband \& Overton, 2010; Wierzbicki \& Pekarik, 1993). Most dropouts occur within the first sessions, which is problematic, since twelve sessions is considered a minimum for a good outcome (Hansen, Lambert \& Forman, 2002). Psychotherapy is an effective treatment for psychological distress and dropouts take no advantage of this. If predictors of therapy dropout are identified, we might be able to better adjust clinical practice to the specific patient in order to motivate the patient to stay in a potentially productive treatment (Lambert, 2004; McMuran et al., 2010). The phenomenon has a great impact on the health care organisation in many complex ways. Resources are wasted, weary therapists are left behind and to even more complicate things studies show that many dropouts are contented with their contact or return within a year (Baekeland \& Lundwall, 1975; Klein, Stone, Hicks \& Pritchard, 2003; Lambert, 2004; Reis \& Brown, 1999; Wierzbicki \& Pekarik, 1993).

Thus, dropping out of psychotherapy is a complex phenomenon with varying occurring rates, impacts and predicting factors. The predicting factors can be divided into three 
clusters: those concerning the patient, the therapist and finally the process. Most thoroughly examined in empirical studies so far are the patient factors. The most important patient factor predicting dropout is the level of socioeconomic status (SES). Persons with high SES are most likely to possess the qualities that predict psychotherapeutic success. High level of education, income and social status are associated with persons who have a strong efficacy over their own life and options of social participation which together seems to constitute the complex structure of completion respectively dropout from psychotherapy (Baekeland \& Lundwall, 1975; Marmot, 2004).

More likely to drop out of psychotherapy are thus individuals with low SES, which is associated with a low level of education, income, lack of power in society and socially strained residential areas and family conditions (Baekeland \& Lundwall, 1975; Hollingshead \& Redlich, 1958; McCabe, 2002; Pekarik, 1985a, Richmond, 1992; Wierzbicki \& Pekarik, 1993). Low SES is also associated with other factors that predict dropout, such as substance abuse, criminality, and certain personality traits such as overall defensive patterns dominated by denial, avoidance and projection but also hostility, aggressiveness, suspiciousness, grandiosity and violent tendencies (Baekeland \& Lundwall, 1975; Lambert 2004; McNair \& Corazzini, 1994; Paivio \& Bahr, 1998; Pekarik 1985a; Richmond, 1992). This is reflected in the therapeutic relationship and makes it difficult for a therapist to form a therapeutic alliance with a patient who has problems coping with issues of dependency, intimacy, trust, distance and autonomy (Lambert 2004; Thormählen et al., 2003). It is more common that these individuals produce external explanations to personal problems but it is also important to acknowledge that persons with low SES actually have less control and influence over their strained life situations, a precondition known to produce psychological distress especially among women (Greenspan \& Mann Kulish, 1985; Magnusson \& Marecec, 2010; McNair \& Corazzini, 1994; Richmond, 1992).

Other common explanations that more represent the relationship and process factors concern dissatisfaction with the therapy or therapist. These are not as thoroughly studied but it is obvious that dropout and dissatisfaction should not be confused since these are different phenomena: dissatisfied patients may stay in therapy as well as satisfied patients may drop out (Beckham, 1992; Garfield, 1963; Lambert, 2004; Pollak, Mordecai, \& Gumpert, 1992). Satisfied and symptom relieved patients experience emotional and relational improvement, enhanced self-understanding and compensatory skills, as well as an overall feeling of life and one's life patterns being more meaningful (Binder, Holgersen \& Nielsen, 2009; Connolly Gibbons, M.B., Crits-Cristoph, Barber, Wiltzey Stirman, Gallop, Goldstein, Temes, \& Ring-Kurtz, 2009). Dropout patients express disappointment about not receiving enough information, validation and support (Lambert, 2004; Reis \& Brown, 1999). They describe their therapists as unsympathetic, passive and indifferent which gives rise to shame and embarrassment (Kolb, Beutler, Davis, Crago, \& Shanfield, 1985; Mohl et al., 1991; Reis \& Brown, 1999). The patients started psychotherapy with expectations that was not fulfilled and not shared with the therapists who, on their part, describe the clients as not understanding what being in psychotherapy involves (Cartwright, Lloyd \& Wicklund, 1980; Pekarik 1985b; Reis \& Brown, 1999; Tryon, 1999). 
The therapist factors, finally, are studied even less. The few studies concerning this factor found significant differences among therapists with regard to frequency of patient dropout and therapeutic outcome (Blatt, Sanislow III, Zuroff \& Pilkonis, 1996; CritsChristoph, Baranackie, Kurcias, Beck, Carroll, Perry, Luborsky, McLellan, Woody, Thompson, Gallagher \& Zitrin, 1991; Luborsky, McLellan, Digeur, Woody \& Seligman, 1997). Lower rates of dropout are related to more experience, flexibility in relation to treatment manuals which correlates with accommodation to the specific problems of the patients, training and own psychotherapy and this also accounts for the level of psychotherapy outcome (Blatt et.al., 1996; Crits-Christoph et.al., 1991; Greenspan \& Mann Kulish, 1985; Luborsky et.al., 1997; Messer \& Wampold, 2002; Norcross \& Wampold, 2011; Richmond, 1992; Roth \& Fonagy, 1996). Therapists using interventions as extensive and early interpretations and confrontations are perceived as unsympathetic and hostile which is a dropout predictor (Crits-Cristoph \& ConnollyGibbons, 2001; Hilsenroth \& Cromer, 2007; Norcross \& Wampold, 2011).

All together these findings converge into the concept of alliance which is surrounded by the more elusive concept of being together - a common factor within psychotherapy largely independent of theory or technique, whose complex importance for therapeutic relationship, process and outcome cannot be overestimated (Norcross \& Wampold, 2011; Messer \& Wampold, 2002). Binder et al. (2009) gave room for patients' own expressions of successful psychotherapy experiences of change. Different aspects of symptom relief were expressed but the superior factor as well as the underlying explanation was the relationship with a "wise, warm and competent professional". Alliance is defined as the patient and therapist sharing common goals or purpose with the therapy, with the patient's sense of safety and trust in the therapy process and in the therapist, while the relational concept of being together describes the many layers of the moment-to-moment intermodal exchange, affect attunement and the matrix of intermodal equivalence in the relationship between patient and therapist. Being together holds the paradox of individuation growing out of symbiosis within the earliest and most basic modes of communication far beyond words (Daniel, 2006; Crits-Cristoph \& Connolly-Gibbons, 2001; Hilsenroth \& Cromer, 2007; Jørgensen, 2004; Kolden et al., 2005; Kumin, 1996; Lambert, 2004; Norcross \& Wampold, 2011; Puchner et al., 2005; Stern, 1985; Stern, 2004). An early established and strong alliance predicts continuation but the contrary does not doom the therapy since the therapist's skill may remedy (Puchner et al., 2005). The skill of the therapist often means an adaptation of interventions, attitude and an overall approach according to the patients' specific needs and difficulties caught within the alliance but even more within the matrix or thickly woven fabric of being together (Crits-Cristoph \& Connolly-Gibbons, 2001; Daniel, 2006; Hilsenroth \& Cromer, 2007; Kolden et al., 2005; Lindgren, Werbart \& Philips, 2010; Kumin, 1996; Norcross \& Wampold, 2011; Stern, 2004). Psychotherapy outcome can be enhanced by matching patient characteristics and therapist qualities (Norcross \& Wampold, 2011).

The dropout phenomenon not only raises problem for the clinical practice. At least a two-folded problem also arises in research. The first considers the definition. Hatchett and Park (2003) summarize this by subdividing the term dropout into four operational definitions represented in the literature to evaluate their concordance with premature terminations. The definitions are (a) therapists judgement, (b) termination by failure to 
attend the last scheduled appointment, (c) median-split procedure, and (d) failure to return after the intake appointment. When examining them the authors find that (a) and (b) both seem to describe the same phenomenon accurately having the same rate of $40 \%$, but (c) and (d) are not, with rates at 53\% and 18\% respectively. No unequivocal recommendation is made but they suggest future researchers to use (b) - the no-show in combination with an outcome evaluation and dissuade from using (c) - not attending enough sessions. These recommendations are made since patients and therapists can agree upon terminate therapy prematurely because of symptom relief. The second fold considers the problem of how to understand the dropout phenomenon. Harris' (1998) summary of this problem consist of three parts: the lack of consensus regarding the definition (which was outlined above), the lack of replication-studies and the problem of simplistic and atheoretical analyses, exemplified by the numerous studies of dropout predictors on a simple client level and the lack of studies with a more complex approach. Norcross and Lambert (2011) confirm this in their review and of evidencebased therapy relationship elements that underlie treatment outcome and effectiveness. Their conclusion is that the many complex connections between patient characteristics, method and practice, and therapist and relational factors need further investigation as well as a comprehensive understanding (Norcross and Lambert, 2011; Norcross \& Wampold, 2011).

Dropping out from psychotherapy is a complex phenomenon indeed, not least in light of the fact that the therapeutic relationship is a dyad with all that implies and where a great importance, but seldom acknowledged, is directed towards the therapist. Regarding this the research focus on preferably client predictors obviously tends to simplify the causal explanations in a problematic way that may result in adjustments of treatment procedures that are inadequate for really addressing the dropout problem. This study tries to address this limitation. The aim is therefore a literature review of the current state of knowledge about therapist, relationship and process factors influencing the dropout phenomenon in individual psychotherapy.

\section{Method}

Databases used for electronic searches in this study were PsychINFO, Pubmed and Cochrane Library. The inclusion criteria were (a) individual psychotherapy, (b) attrition or dropout or discontinuation, (c) predictors, (d) adults and (e) publication between 2000 and 2011. Searches were then performed in titles, abstracts and keywords. An extensive reading process started. By reading titles, abstracts and keywords several studies were excluded according to the following principles: studies concerning forensic care, in-care or compulsory care, addiction, and finally medication treatment with or without psychotherapy. The remaining studies were then read in full and those not meeting the criterion of relating dropout rates to therapist or process factors were excluded. McMuran et al.'s (2010) systematic review of non-completion in personality disorder treatments has served as an overall model for this study.

Being a review the study methodically aims to gather and overview existing information and knowledge about a certain phenomenon. 


\section{Results}

The last searches were made by January 2011 in all three databases and by then 1153 studies were electronically identified using the inclusion criterions. By using the exclusion criterions when reading titles and abstracts the number of studies could be gradually reduced to 201. Closer reading of these studies excluded further 161 studies. The remaining 40 studies are included in the review and reported in Table 1 and below.

The 40 studies were carried out in twelve countries in the Western world: USA (22), Britain (3), Austria (3), Germany (2), Sweden (2), Italy (2), and 1 study each in Brazil, Canada, Spain, Greece, Norway and Israel. No study was found from Australia, Asia or Africa. One study was published in German, one in Portuguese and the rest in English. Of the 40 studies four were reviews, two were meta-analyses, 33 were quantitative studies and one was qualitative. The number of participants was specified in 35 of the studies and all together they amount 34,972 participants, ranging from 6 to 22,095 with a mean of a thousand participants in each study.

Diagnoses were specified in 22 studies. Mood Disorders, Anxiety Disorders and Personality Disorders dominate. The proportion of women was specified in 30 of the included studies. Women dominate, ranging from 51 to 100 percent with a mean of 68 percent. All studies concerned individual psychotherapy since this was one of the inclusion criterions. The type of psychotherapy was specified in half of the studies. Psychodynamic psychotherapy and cognitive behavioural therapy dominated but other types were represented as well. Duration was specified in seven studies. Two of these concerned specific therapy models (Horwitz' psychodynamic model and Luborsky's supportive-expressive psychotherapy), three of them stated a mean number of sessions, and two stated a minimum number of sessions that was also related to the definition of dropout.

Dropout was defined and rated in 26 of the studies. The four reviews left both these concepts unspecified, the two meta-analyses as well, in three of the studies dropout was the inclusion criterion and was not otherwise specified and in further five studies they were simply not specified for different reasons. The rates of dropout varied strongly between 12 and 69 percent with a mean of 39 percent. Recalling Hatchett and Park's (2003) distinction between four operational definitions the 27 studies used either (b) not showing up (16) or (c) a median-split procedure with the patient ending before a certain number of sessions or time-limit (10). The variation was stronger using the median-split procedure, between 12 and 69 percent, than using termination by failure to attend the last scheduled appointment, 15-53 percent, but the mean was 39 percent in both cases.

Therapist factors behind dropouts were specified in 22 of the studies. Within this factor twelve subordinated factors emerged. The therapist's education, experience and age influenced dropout in six studies. The therapist showing empathy, warmth and regard predicted continuation in five studies. Reminding about appointments, calling when missed and being supportive in a concrete manner predicted continuation in four studies. Gender and ethnicity of the therapist was a focused factor in four studies. They showed that this factor did not influence dropout rates in itself but still demonstrating that gender and ethnicity of the therapist gave specific competence that affected their ability as therapist with different patients which in the long run could influence dropout. 


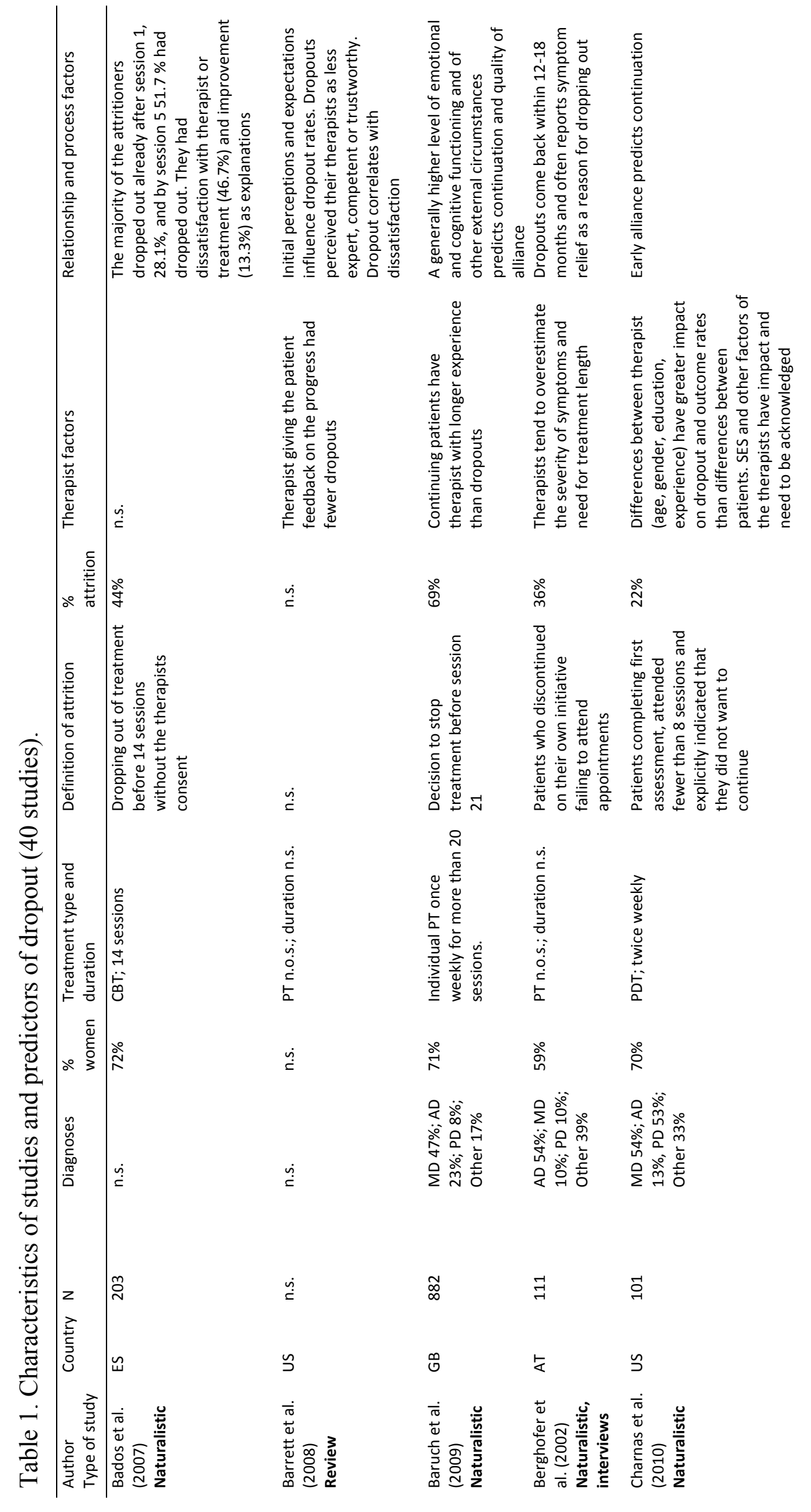



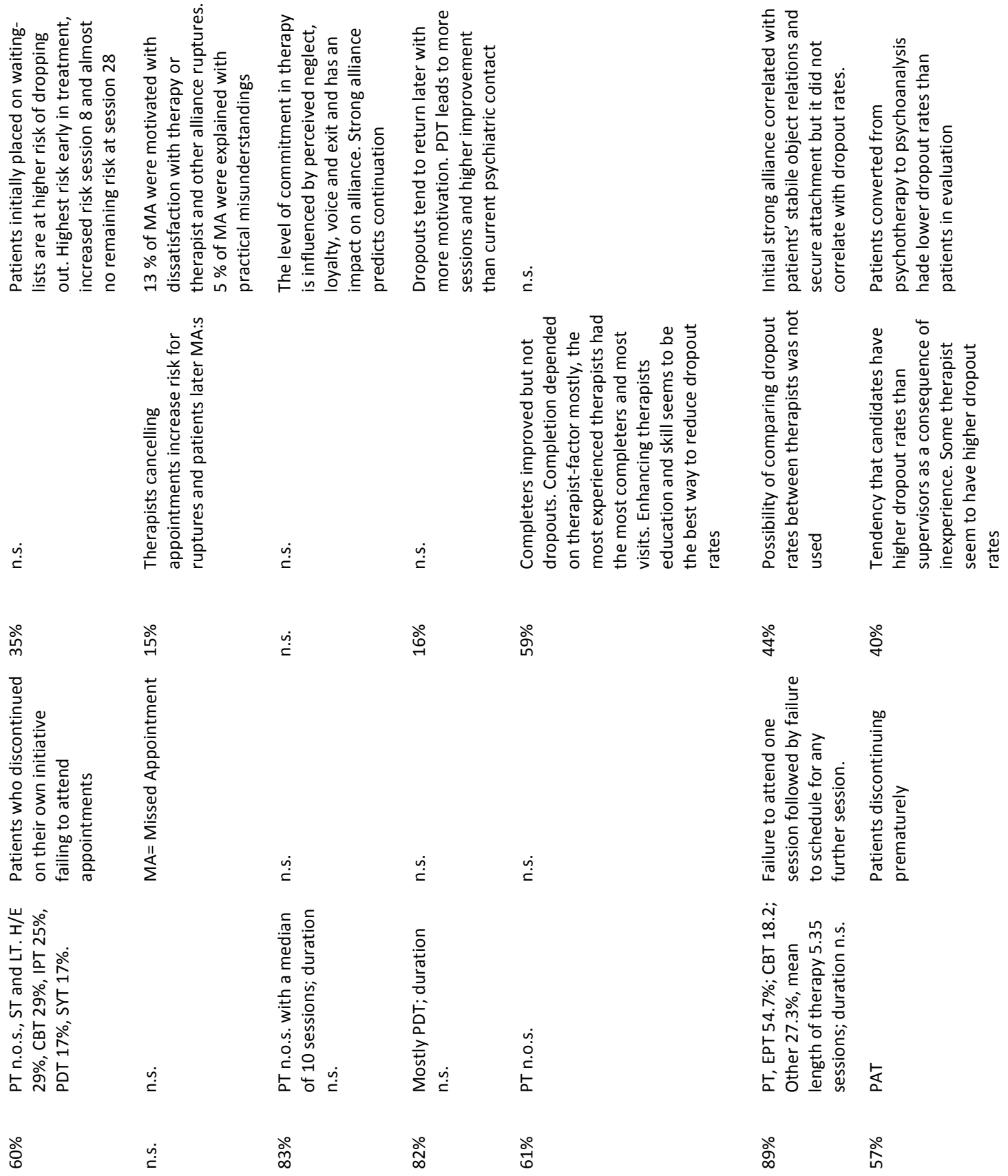

ฌे

ญิ

เั้

ळ

ฝे

نั

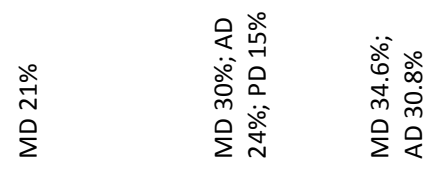

ণ্

䎹

$\stackrel{\infty}{\rightarrow}$

s̆

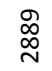

出告

号

3

ร

แ

บ

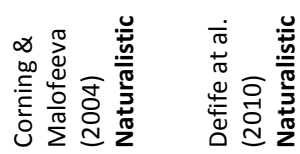

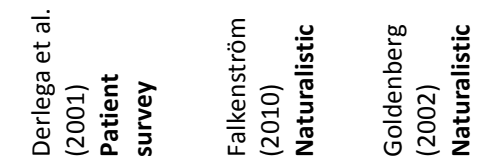

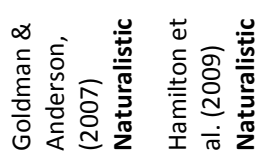



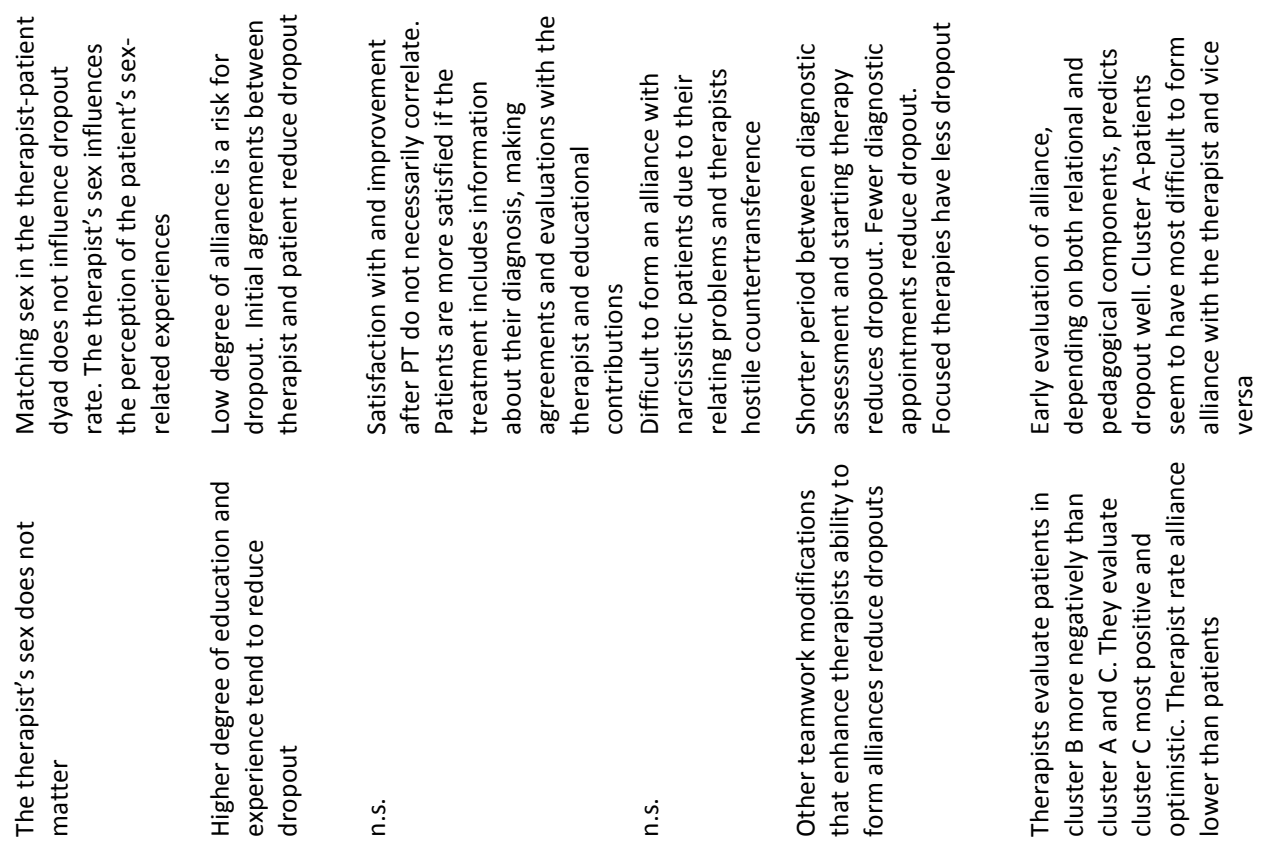

๖̊

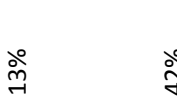

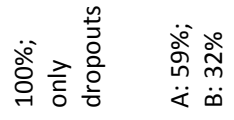

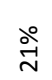
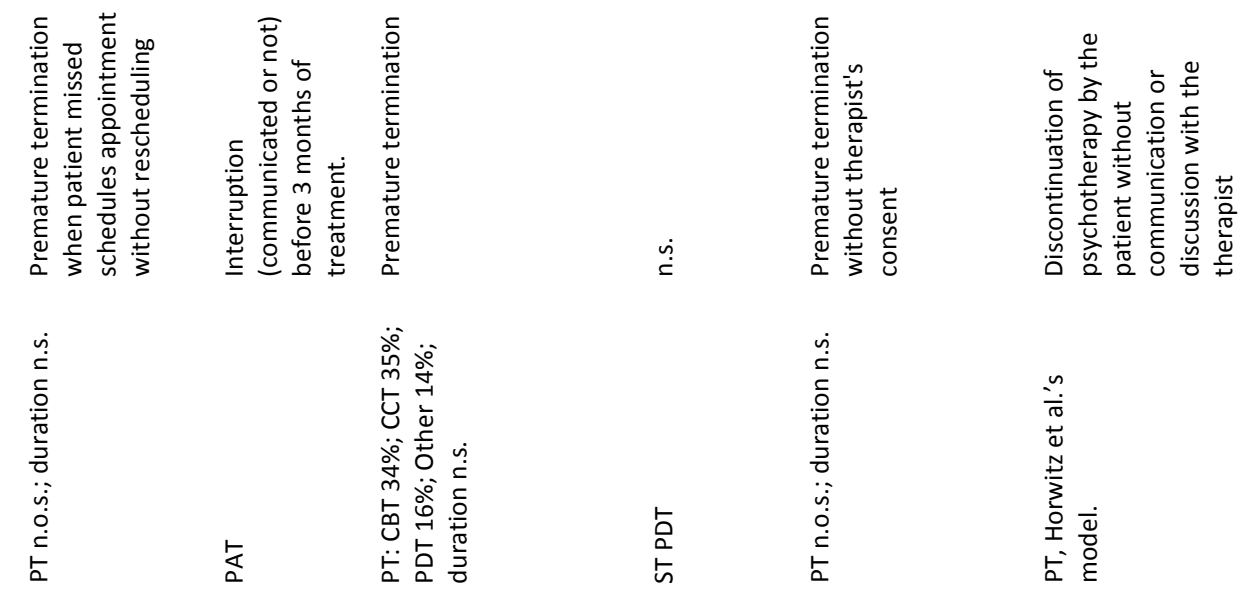

ฌे

なें

ㅇํㅁ

$\dot{\dot{s}} \quad \stackrel{\dot{g}}{\dot{s}}$

১̊ㅇ

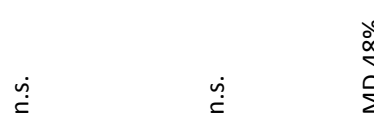





के

$\stackrel{\dot{s}}{\check{c}}$

옹

ก 愛㟔

岁 守

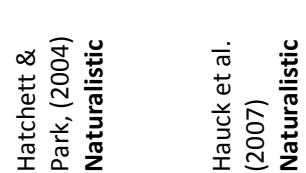

㟔㟔

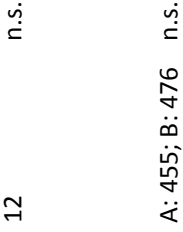

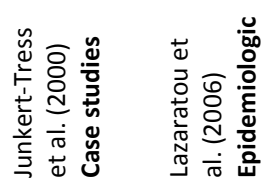

上

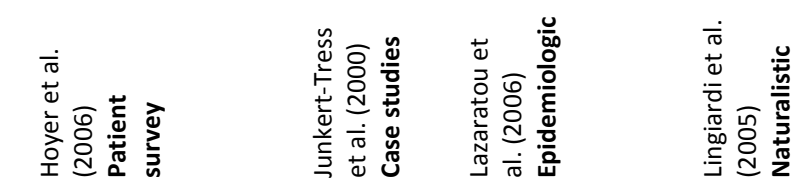



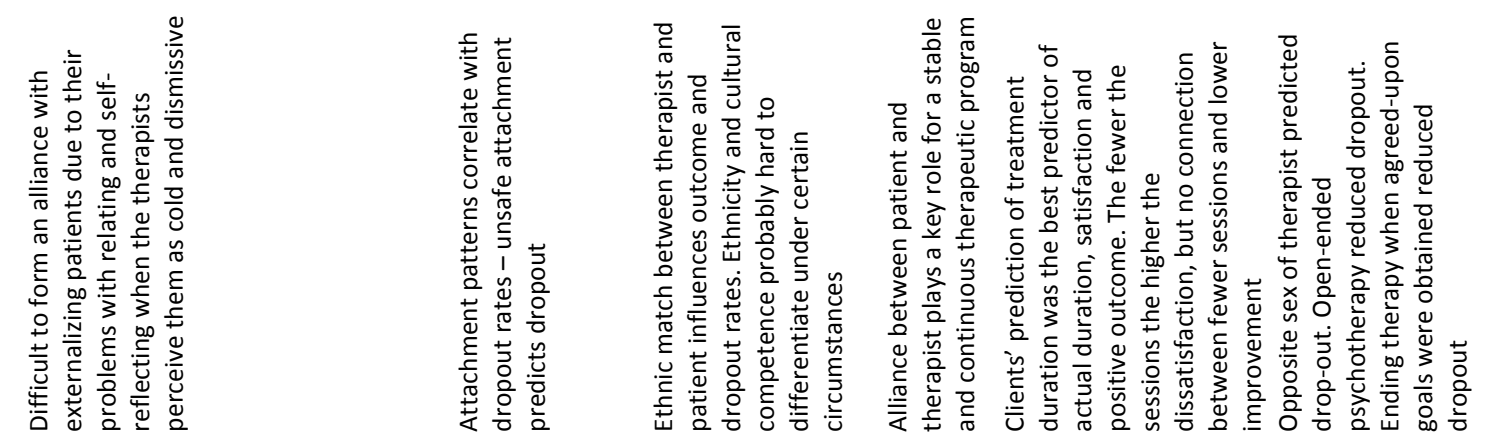

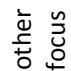
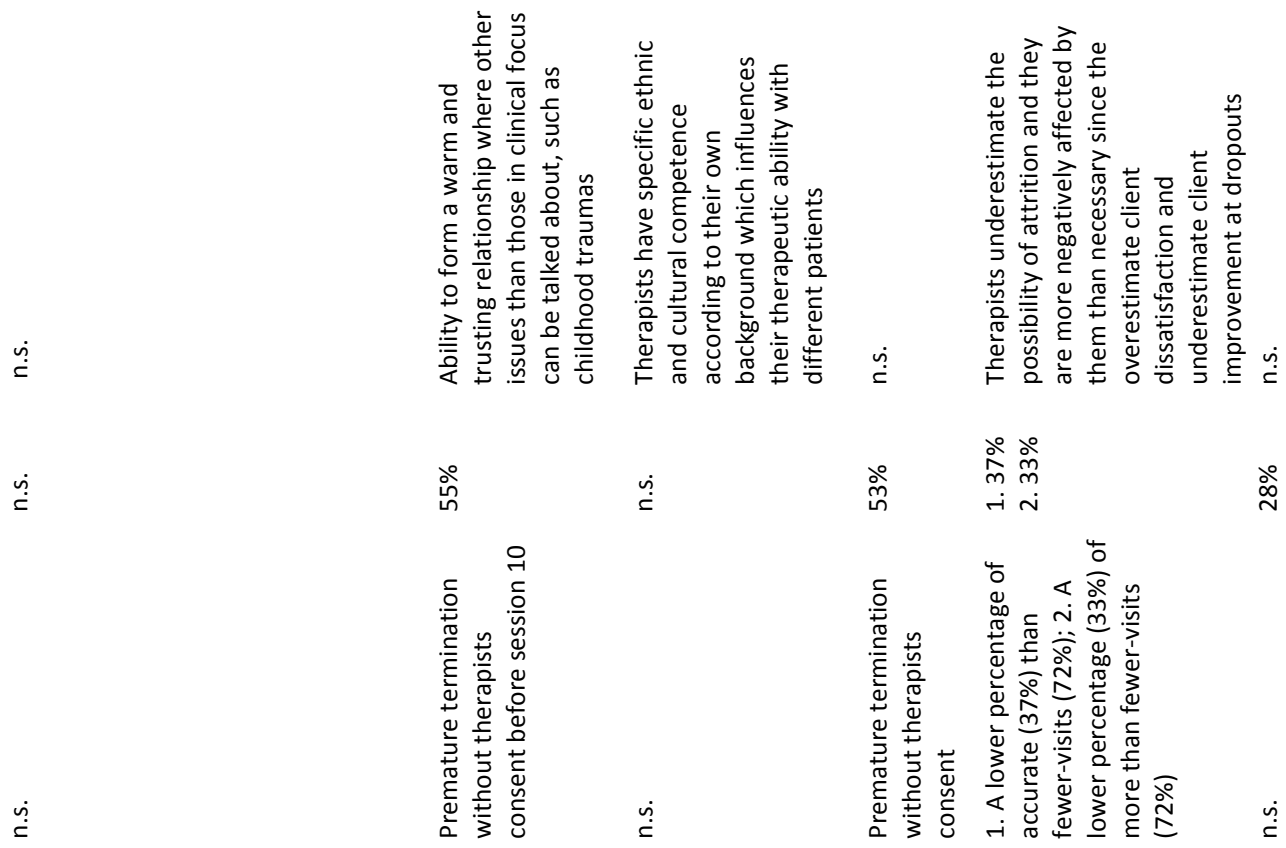

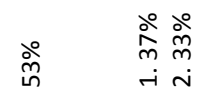

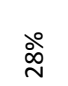

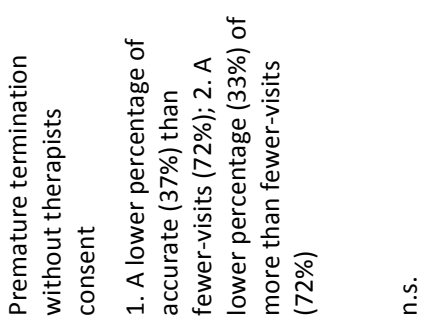


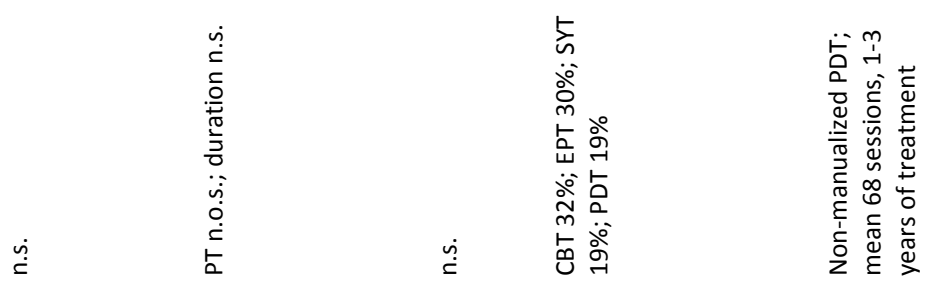

急璦

寒

拣 荤

ळे

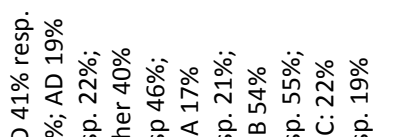

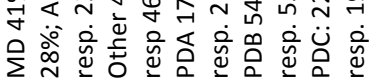
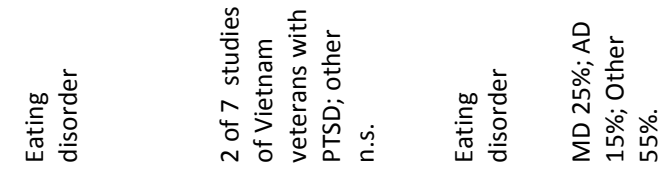

응



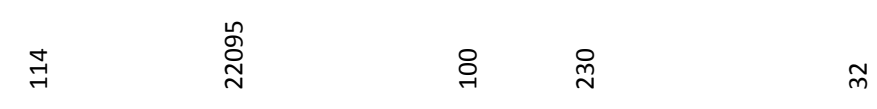

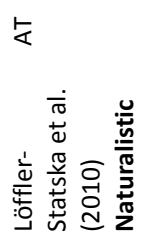

\%

s

$=3$

울



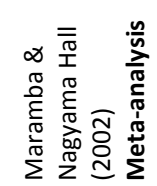

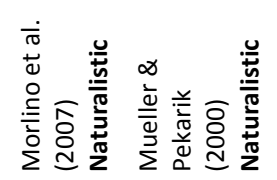

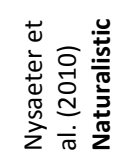




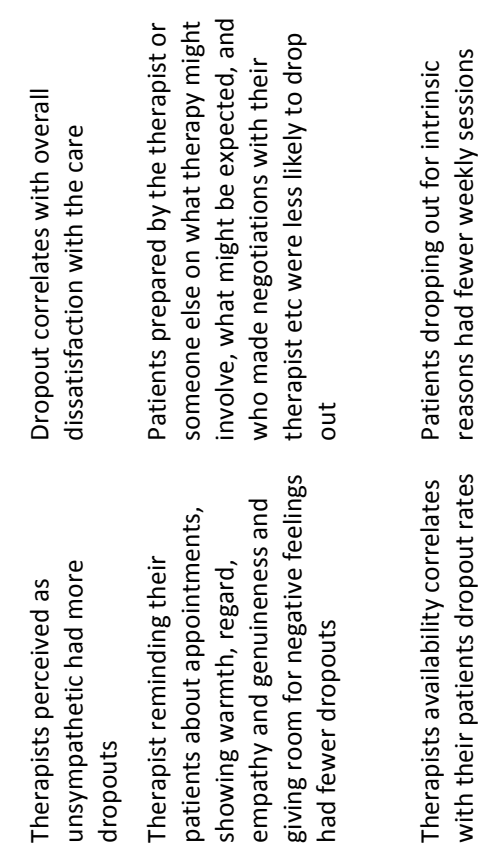

品

แั่

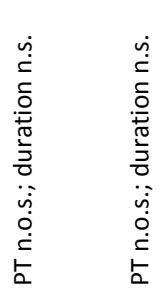

它

ֻั่

壱

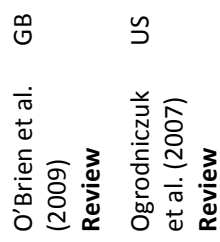

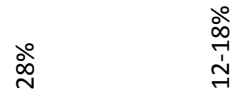
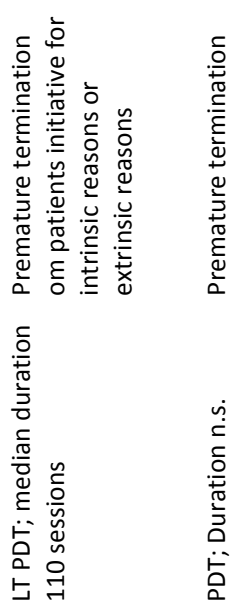

’ำ

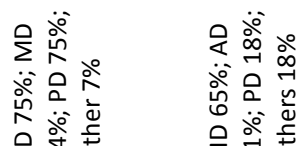
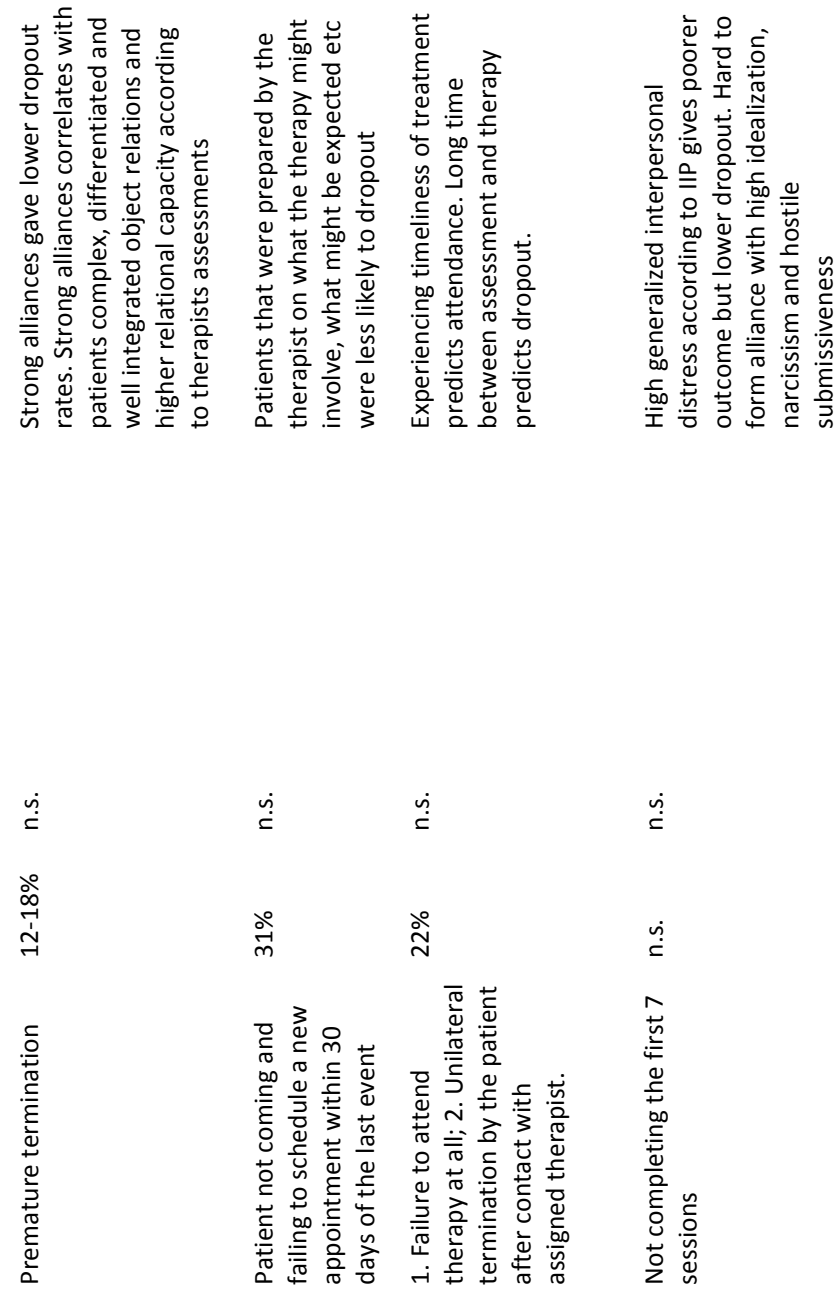

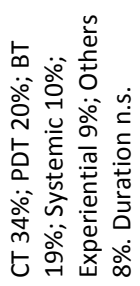

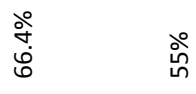

ถั่

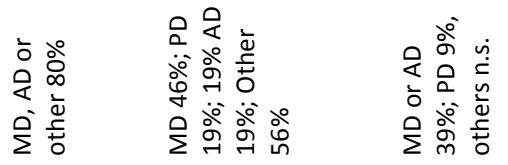

in

in

$\stackrel{\sim}{\approx} \quad \stackrel{m}{m}$

สิ

ธง

\&

ร

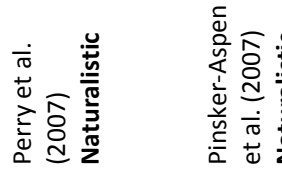

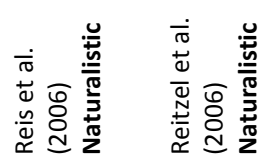



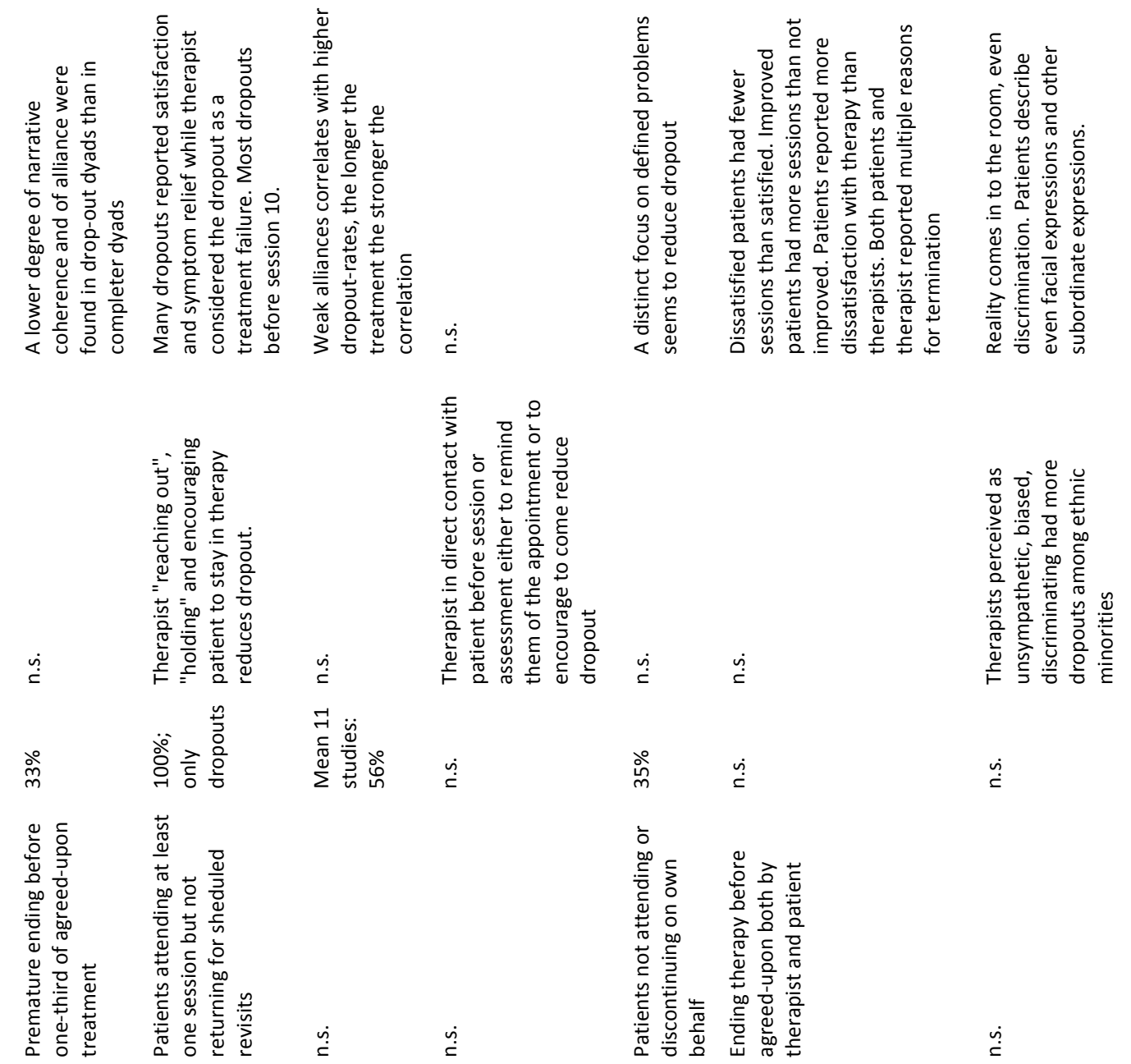



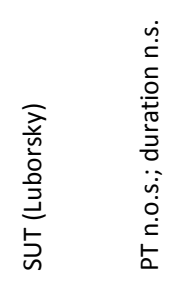

$\stackrel{\dot{s}}{\check{c}}$

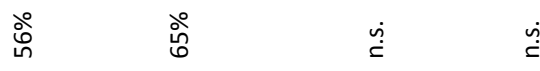

今े

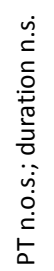

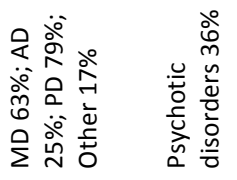

$\stackrel{\infty}{+}$

$\infty$

$\stackrel{\overrightarrow{0}}{\vec{m}} \quad \dot{\varphi}$

$\infty \quad \stackrel{\sim}{7}$

$\stackrel{\dot{s}}{\dot{x}}$

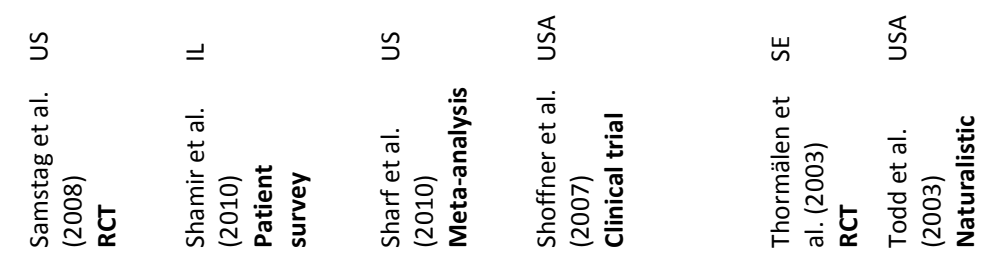



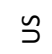

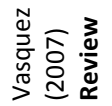




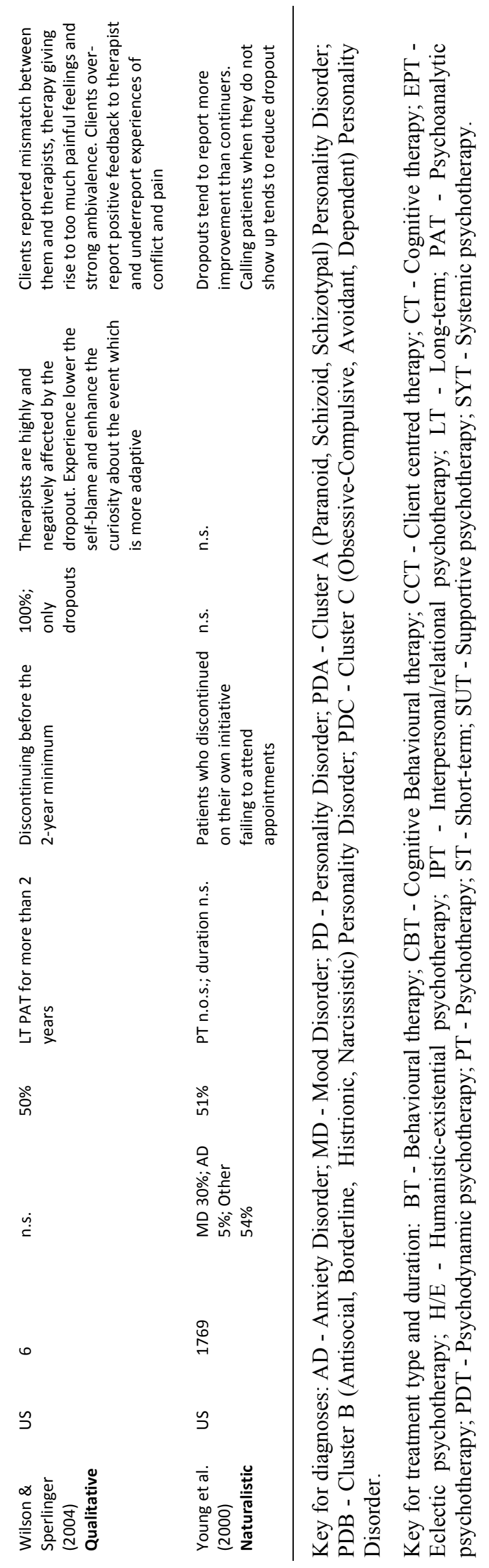


Therapists perceived as biased or unsympathetic had more dropouts in three studies. These factors obviously influence the therapeutic relationship. For example, patients in one study described sublime therapist reactions as tone of voice, glance in eyes as important for feelings of being understood and accepted. Therapist with access to team of colleagues or tutorials, education and organisational support had fewer dropouts in two studies. Therapist not giving room for negative affects or perceptions of the therapeutic relationship or of the process increased risk for dropout in two studies. In one study each three further factors influenced the dropout rates. Therapists cancelling appointments, not giving feedback on the progress, and responding more negatively to patients with cluster B personality disorders had more dropouts. Finally, two additional factors were found though not immediately related to dropout but still important for understanding the phenomenon. In two studies therapists were showed to overestimate the length of the contact and severity of symptoms, thereby giving rise to premature endings or misunderstandings. In another study the authors found extensive individual differences in dropout rates between therapists and had material for lining out these but explicitly chose not to while concluding that all the therapists in the study had dropouts anyway.

Relationship and process factors behind dropout were specified in 38 of the studies and ten subordinated factors emerged. The quality of the alliance influenced dropout rates in sixteen studies. Strong alliance early in the process predicted continuation in the studies. Dropouts occur in over half of the cases before session five. Sparse contact, lack of timeliness between the first contact and starting therapy or few appointments increased risk for dropout in seven studies. Preparation and information about therapy, expectations and preferences beforehand predicted continuation in six studies. A general dissatisfaction about the therapist or the therapy predicted dropout in five studies. In five studies gender or ethnic mismatch between therapist and patient predicted dropout. Focusing after agreeing upon central problems predicted continuation in two studies. Attachment patterns were examined in one study showing that counter-matching of patterns between therapist and patient worked out better than matching when comparing dropout rates. Three final subordinated factors emerged in eight studies that cannot directly be classified as influencing factors but they are still important parts of the phenomenon. Patients dropping out from treatment are not necessarily patients that have experienced lack of improvement, but rather the opposite, which is clearly shown in four studies. Patients dropping out gave rise to misunderstandings in two studies: therapist considered the occurrences failures while the patients turned out being satisfied and relieved of symptoms which is concordant with above. Dropouts returned within less than 18 months to treatment in two studies.

\section{Discussion}

\section{The common knowledge}

Previously well known facts about psychiatric outpatients in general and dropout especially were confirmed in this review. The most common diagnoses were Mood Disorders, Anxiety Disorders and Personality Disorders which is concordant with findings from psychiatric outpatient services. Women's domination is also falling into the category of well known facts, especially since forensic care settings and substance abuse clinics, where men dominate among patients, were excluded from this review. 
The dropout rates varied strongly but were constantly high with a mean of almost 40 percent, some percentages higher than in previous reviews of dropout. This could be an effect of the focus in the included studies on dropouts specifically. When defining a patient not showing up to an appointment as a dropout the phenomenon is probably more exactly caught than defining dropout as the patient not attending enough number of sessions. The rates varied less for no-shows and the rates where not at the same risk of being biased by the fact that many therapists and patients agree upon earlier endings because of symptom relief. One study defined dropout as attending fewer than 21 sessions and that could be considered as almost asking for an unfairly high dropout rate $(69 \%)$. The high dropout rates produced by the median-split procedure probably reflect other phenomena within the psychotherapy field especially the fact that therapy, as all other relationships in life, consists of constant renewals of agreements such as abridged length of therapy because of symptom relief. These are at least as important but in the periphery of the dropout phenomenon.

As well known, or even as expected, these findings may be they are of no less importance. Confirmed over and over again they convincingly describe the psychiatric reality when it comes to these fundamental conditions.

Another well known fact confirmed here and probably more reflecting the research reality than the clinical practice is the sparse focus on therapist factors especially but also on relationship and process factors behind dropouts in comparison with the extensiveness of studies focusing on patient factors. The importance of SES and the difficulties produced by patients with personality disorders, especially cluster B, is confirmed over and over again. Living under social and economical strains could be considered as a vicious circle. Such life circumstances in themselves produce psychological distress and suffering expressed both by women, dominating among psychiatric patients, and men, dominating in forensic care and substance abuse clinics. Especially women and patients from ethnic minorities express in the studies a wish to match the therapist's gender or ethnicity to one's own. This reflects probably an experience of being different or deviant, not understood, misunderstood or even worse discriminated, maybe with feelings of shame and embarrassment. The effect of such distress, the hopelessness and powerlessness, the stigma left by a history of forensic care might aggravate the strained life conditions as well as the perceptions of unsympathetic and unsupportive therapists give rise to dropout and actually not being helped. Again, patients factors in general and the SES-factor especially are of no less importance in describing the fundamental conditions of the psychiatric reality but important angles of the dropout phenomenon are still left in darkness, such as the therapist and the relationship and process factors.

\section{The common factors}

This review distinguishes between therapist and relationship and process factors, each of them divided into several subordinated factors (summarized in Table 2). There are differences between those factors but, after all, almost all of them could be converged into therapeutic alliance and definitely all of them into the relational and common factor of being together. Building a strong alliance early in the process predicts continuation. 
Table 2. Therapist and relationship/process factors contributing to dropout; number of publications per subordinated factor (several subordinated factors might appear in each study). Factors in italics represent those not immediately influencing dropout but still important for understanding the phenomenon.

\begin{tabular}{|c|c|}
\hline Factor & Frequency \\
\hline Therapist factors & 22 \\
\hline Education, experience and age & 6 \\
\hline Empathy, warmth and regard & 5 \\
\hline Concrete support (reminding about appointments for example) & 4 \\
\hline Gender and ethnicity & 4 \\
\hline Unsympathetic, biased therapists & 3 \\
\hline Denying of negative affects & 2 \\
\hline Team of colleagues, organisational support & 2 \\
\hline Cancellations made by therapists & 1 \\
\hline Not giving feedback & 1 \\
\hline Negative responses & 1 \\
\hline Initial overestimation of treatment length or severity of symptoms & 2 \\
\hline Not investigating obvious differences between therapists & 1 \\
\hline Relationship and process factors & 38 \\
\hline Quality of alliance & 16 \\
\hline Sparse contact or few appointments & 7 \\
\hline Patient dissatisfaction & 5 \\
\hline Mismatch of gender and/or ethnicity & 5 \\
\hline Preparation, information & 6 \\
\hline Central focus & 2 \\
\hline Counter-matching attachment patterns & 1 \\
\hline Misunderstandings & 2 \\
\hline Returning before 18 months after dropout & 2 \\
\hline Dropout $\neq$ lack of improvement & 4 \\
\hline
\end{tabular}

Preparing and informing about what it takes, dense appointments and a concrete holding by reminding about appointment as a non-evaluative hands-on way of addressing external difficulties is all a way of strengthening the initial alliance. Timeliness between intake and psychotherapy start is a factor mentioned in the studies as influencing dropout rates. However, this factor also contains those in recent studies called the nonstarters, i.e. those that not start in agreed-upon therapy at all, and they partly differentiate from dropouts. Showing empathy, being sympathetic and attentive towards the patient, accommodating to the patient's needs, focusing on central issues that are agreed upon, giving feedback on the progress and giving room for negative affects 
primarily, all this describes the relational flow of being together which secondarily further strengthen alliance. Dissatisfaction and misunderstandings could then be considered aspects of a weak alliance and ruptures in the relationship. Quality of alliance is therefore an aspect of time passing. Dropout occurs most frequently early within the first sessions, while late dropouts occur somewhere between rarely and never. Alliance is in its turn held by the relationship; the concept of being together which is a thick fabric woven of threads of all colours and materials in many layers.

Although alliance and the concept of being together counts as a relationship and process factors it still weighs heavier on the therapist to form an alliance and build a relationship that holds on for continuation and a psychotherapeutic good outcome. The therapeutic relationship is always unequal and asymmetric and the responsibility for continuation and outcome may never be evenly shared between therapist and patient. Some of the studies clearly show that the therapist factor, consisting of such components as the therapist's skills, degree of education and experience, is a superior factor that in the end rules out every other factor. A skilled therapist handles attachment patterns, difficulties, needs, wishes and character traits of the patient adaptively and accordingly in order to secure continuation and a positive progress in therapy. The very same studies that report patients wishing matching of gender and ethnicity with their therapists also report that mismatching does not need to end with dropout, just as an initially weak alliance does not have to remain weak as long as the therapist is skilled enough. Other studies not included in this review confirm this and also supports the occasional need for matching patient characteristics and therapist qualities.

\section{The context of skill}

The skilled therapist rises up from the reviewed studies as a professional person with a contradictory competence at first glance. A skilled therapist builds a strong early alliance by not giving cancellations or sparse appointments and protects the relationship from ruptures, still taking negativity, disappointments and hardly bearable affects into the room. A skilled therapist holds on to psychotherapeutic frames while unorthodoxly going beside them in different ways when it is called for. Previous studies have shown that a flexible relation to treatment manuals for the benefit of accomodation to specific needs of the patients distinguishes skilled therapists - which is considered as another facet of the contradictory spectra of psychotherapy. Skill seems to be the knowledge, handling and endurance of contradictions and paradoxes coming alive when two worlds meet - not to collide, nor repel, nor fuse - simply "the paradox of individuation out of a symbiotic matrix of intermodal equivalence" by using "pre-object modes of communication in the clinical situation" (Kumin, 1996, p. 74). In this way skill demands intuition, a know-how, which could be seen as an exponential effect of education, training and experience working together. Even patients dropping out, which will occur no matter how skilled the therapist might be, add to knowledge provided openness and curiosity about the phenomenon in the therapist, among the peers and colleagues and in the organisation. Skill is not a certain amount of knowledge carried inside the therapist. Skill is also an aspect and a reflection of its context, met and reflected in the peers, supported and enhanced by the organisation offering education, training and support. Everything counts in a world of constant complexity of the psychotherapeutic situation. 


\section{Clinical implications}

Implications for further clinical practice are briefly summarized in point form below.

- Thorough examination of the patient characteristics, expectations, perceptions and needs with an according treatment adaptation gives the best predictor of psychotherapy continuation and outcome and securing of success.

- $\quad$ Preparation and pedagogical elements beforehand enhance continuation.

- Since the therapists skill, an aspect of education, training and experience, is of overwhelming importance, it needs constant enhancement and development by education and training with a continuous feedback on the progress and development of the therapeutic alliance as well as support by team and organisation.

\section{Advantages and limitations}

Meeting problems and searching knowledge from the opposite angle or in the opposite direction is known to be an effective method. What works for whom in psychotherapy can be understood by studying the void a dropout leaves as well as the fabric of the relationship becomes visible through the rip the rupture caused. Just as long the lightning of the phenomenon is broad enough.

This review might be biased in the following way: no additional reader made an objective evaluation of the relevance of the included studies or any objective evaluation of the sorting between therapist and process factors. AW, however, functioned as such, except from being my supervisor, and I am grateful to him for his everlasting pursuit for consensus with me. Furthermore, this study is limited to patient-initiated dropout, as none of the included studies specified therapist-initiated discontinuation of therapy. 


\section{References \\ ( ${ }^{*}$ Asterisk denotes studies included in the review)}

*Bados, A., Balaguer, G., \& Saldaña, C. (2007). The efficacy of cognitive-behavioral therapy and the problem of drop-out. Journal of Clinical Psychology, 63, 585-592.

Baekeland, F., \& Lundwall, L. (1975). Dropping out of treatment: A critical review. Psychological Bulletin, 82, 738-783.

*Barrett, M.S., Chua, W-J., Crits-Christoph, P., Gibbons, M.B., \& Thompson, D. (2008). Early withdrawal from mental health treatment: Implications for psychotherapy practice. Psychotherapy: Theory, Research, Practice, Training, 45, 247-267.

*Baruch, G., Vrouva, I., \& Fearon, P. (2009). A follow-up study of characteristics of young people that dropout and continue psychotherapy: Service implications for a clinic in the community. Child and Adolescent Mental Health, 14, 69-75.

Beckham, E.E. (1992). Predicting patient dropout in psychotherapy. Psychotherapy: Theory, Research, Practice, Training, 29, 177-182.

*Berghofer, G., Schmidl, F., Rudas, S., Steiner, E., \& Schmitz, M. (2002). Predictors of treatment discontinuity in outpatient mental health care. Social Psychiatry and Psychiatric Epidemiology, 37, 276-282.

Binder, P.E., Holgersen, H., \& Høstmark Nielsen, G. (2009). Why did I change when I went to therapy? A qualitative analysis of former patients' conceptions of successful psychotherapy. Counselling and Psychotherapy Research, 9, 250-256.

Blatt, S.J.; Sanislow, C.A. III; Zuroff, D.C. \& Pilkonis, P.A. (1996). Characteristics of effective therapists: Further analysis of data from the National Institute of Mental Health Treatment of Depression Collaborative Research Program. Journal of Consulting and Clinical Psychology, 64, 1276-1284.

Cartwright, R., Lloyd, S., \& Wicklund, J. (1980). Identifying early dropouts from psychotherapy. Psychotherapy: Theory, Research, Practice, Training, 17, 263-269.

*Charnas, J.W., Hilsenroth, M.J., Zodan, J., \& Blais, M.A. (2010). Should I stay or should I go? Personality Assessment Inventory and Rorschach indices of early withdrawal from psychotherapy. Psychotherapy: Theory, Research, Practice, Training, 47, 484-499.

Chiesa, M., Wright, M., \& Neeld, R. (2003). A description of an audit cycle of early dropouts from an inpatient psychotherapy unit. Psychoanalytic Psychotherapy, 17, 138-149.

Connolly Gibbons, M.B., Crits-Cristoph, P., Barber J.P., Wiltzey Stirman, S., Gallop, R., Goldstein, L.A., Temes, C.M., \& Ring-Kurtz, S. (2009). Unique and common factors of change across cognitive and dynamic psychotherapies. Journal of Consulting and Clinical Psychology, 77, 801-813.

*Corning, A.F., \& Malofeeva, E.V. (2004). The application of survival analysis to the study of psychotherapy termination. Journal of Counseling Psychology, 51, 354-367.

Crits-Christoph, P.; Baranackie, K.; Kurcias, J.S.; Beck, A.T.; Carroll, K.; Perry, K.; Luborsky, L.; McLellan, T.; Woody, G.E.; Thompson, L.; Gallagher D., \& Zitrin, C. (1991). Meta-analysis of therapist effects in psychotherapy outcome studies. Psychotherapy Research, 1, 81-91.

Crits-Cristoph, P., \& Connoly Gibbons, M.B. (2001). Relational interpretations. Psychotherapy: Theory, Research, Practice, Training, 38, 423-428. 
Daniel, S.I.F. (2006). Adult attachment patterns and individual psychotherapy: A review. Clinical Psychology Review, 26, 968-984.

*Defife, J.A., Conklin, C.Z., Smith, J.M., \& Poole, J. (2010). Psychotherapy appointment no-shows: Rates and reasons. Psychotherapy: Theory, Research, Practice, Training, 47, 413-417.

*Derlega, V.J., McIntyre, R., Winstead, B.A., \& Morrow, G. (2001). A preliminary study of attractionbarrier model of patients' commitment and responses to dissatisfaction in psychotherapy. Psychotherapy: Theory, Research, Practice, Training, 38, 283-296.

*Falkenström, F. (2010). Does psychotherapy for young adults in routine practice show similar results as therapy in randomized clinical trials? Psychotherapy Research, 20, 181-192.

Garfield S.L. (1963). A note on patients' reasons for terminating therapy. Psychological Reports, 13, 38.

*Goldenberg, V. (2002). Ranking the correlates of psychotherapy duration. Administration and Policy in Mental Health, 29, 201-214.

*Goldman, G.A., \& Anderson, T. (2007). Quality of object relations and security of attachment as predictors of early therapeutic alliance. Journal of Counseling Psychology, 54, 111-117.

Greenspan, M., \& Mann Kulish, N. (1985). Factors in premature termination in long-term psychotherapy. Psychotherapy: Theory, Research, Practice, Training, 22, 75-83.

*Hamilton, M., Wininger, L., \& Roose, S.P. (2009). Dropout rates of training cases: Who and when. Journal of the American Psychoanalytic Association, 57, 695-702.

Hansen, N.B., Lambert, M.J., \& Forman, E.M. (2002). The psychotherapy dose-response effect and its implications for treatment delivery services. Clinical Psychology: Science and Practice, 9, 329343.

Harris, P.M. (1998). Attrition revisited. American Journal of Evaluation, 19, 293-305.

Hatchett, G.T., \& Park, H.L. (2003). Comparison of four operational definitions of premature termination. Psychotherapy: Theory, Research, Practice, Training, 40, 226-231.

*Hatchett, G.T., \& Park, H.L. (2004). Revisiting relationships between sex-related variables and continuation in counseling. Psychological Reports, 94, 381-386.

*Hauck, S., Kruel, L., Sordi, A., Sbardelotto, G., Cervieri, A., Moschetti, L., Shestatsky, S., \& Freitas Caitlin, L.H. (2007). Factors related to early dropout in psychoanalytic psychotherapy. Revista de Psiquiatria do Rio Grande do Sul, 29, 265-267. DOI: 10.1590/S0101-81082007000300005.

Hilsenroth, M.J., \& Cromer, T.D. (2007). Practice review. Clinician interventions related to alliance during the initial interview and psychological assessment. Psychotherapy: Theory, Research, Practice, Training, 44, 205-218.

Hollingshead, A.B., \& Redlich, F.C. (1958). Social class and mental illness. New York: John Wiley.

*Hoyer, J., Helbig, S., \& Wittchen, H-U. (2006). Experiences with psychotherapy for depression in routine care: A naturalistic patient survey in Germany. Clinical Psychology and Psychotherapy, 13, 414-421.

*Junkert-Tress, B., Tress, W., Hildenbrand, G., Windgassen, F., Schmitz, N., Hartkamp, N., \& Franz, M. (2000). Der Behandlungsabbruch: Ein multifaktorielles Geschehen [Premature termination: A multifactoral phenomenon]. Psychotherapie, Psychosomatik, Medizinische Psychologie, 50, 351365. DOI: $10.1055 / \mathrm{s}-2000-9098$ 
Jørgensen, C.R. (2004). Active ingredients in individual psychotherapy: Searching for common factors. Psychoanalytic Psychology, 4, 516-540.

Kazdin, A.E., \& Mazurick, J.L. (1994). Dropping out of child psychotherapy: Distinguishing early and late dropouts over the course of treatment. Journal of Consulting and Clinical Psychology, 62, 1069-1075.

Kolb, D.L., Beutler, L.B., Davis, C.S., Crago, M., \& Shanfield, S.B. (1985). Patient and therapy variables relating to dropout and change in psychotherapy. Psychotherapy: Theory, Research, Practice, Training, 22, 702-710.

Kolden, G.G., Klein, M.H., Strauman, T.J., Crisholm-Stockard, S., Heerey, E., Schneider, K.L., \& Smith, T.L. (2005). Early psychotherapy process and cluster B and C personality pathology: Similarities and differences in interactions with symptomatic and interpersonal distress. Psychotherapy Research, 15, 165-177.

Kumin, I. (1996). Pre-object relatedness: Early attachment and the psychoanalytic situation. New York: Guilford Press.

Lambert, M.J. (Ed.) (2004). Bergin and Garfield's handbook of psychotherapy and behavior change (5th ed.). New York: Wiley.

*Lazaratou, H., Anagnostopoulos, D.C., Vlassopoulos, M., Tzavara, C., \& Zelios, G. (2006). Treatment compliance and early termination of therapy: A comparative study. Psychotherapy and Psychosomatics, 75, 113-121.

Lindgren, A., Werbart, A., \& Philips, B. (2010). Long-term outcome and post-treatment effects of psychoanalytic psychotherapy with young adults. Psychology and Psychotherapy: Theory, Research and Practice, 83, 27-43.

*Lingiardi, V., Filipucci, L., \& Baiocco, R. (2005). Therapeutic alliance evaluation in personality disorders psychotherapy. Psychotherapy Research, 15, 45-53.

Luborsky, L.; McLellan, A.T.; Digeur, L.; Woody G., \& Seligman, D.A. (1997). The psychotherapist matters: Comparison of outcomes across twenty-two therapist and seven patient samples. Clinical Psychology: Science and Practice, 4, 53-65.

*Löffler-Statska, H., Blueml, V., \& Boes, C. (2010). Exploration of personality factors and their predictive impact on therapy utilization: The externalizing mode of functioning. Psychotherapy Research, 20, 295-308.

Magnusson, E., \& Marecec, J. (2010). Genus och kultur i psykologi: Teorier och tillämpningar. Stockholm: Natur och Kultur.

*Mahon, J., Bradley, S.N., Harvey, P.K., Winston, A.P., \& Palmer, R.L. (2001). Childhood trauma has dose-effect relationship with dropping out from psychotherapeutic treatment for bulimia nervosa: A replication. International Journal of Eating Disorders, 30, 138-148.

*Maramba, G.G., \& Nagyama Hall, G.C. (2002). Meta-analyses of ethnic match as a predictor of dropout, utlization, and level of functioning. Cultural Diversity and Ethnic Minority Psychology, 8, 290297.

Marmot, M. (2004). The status syndrome: How social standings affects our health and longevity. New York: Holt \& McDougal.

McCabe, K.M. (2002). Factors that predict premature termination among Mexican-American children in outpatient psychotherapy. Journal of Child and Family Studies, 11, 347-359. 
McMuran, M., Huband, N., \& Overton, E. (2010). Non-completion of personality disorder treatments: A systematic review of correlates, consequences, and interventions. Clinical Psychology Review, 30, 277-287.

McNair, R.R., \& Corazzini, J.G. (1994). Client factors influencing group therapy dropout. Psychotherapy: Theory, Research, Practice, Training, 31, 352-362.

Messer, S.B., \& Wampold, B.E. (2002). Let's face facts: Common factors are more potent than specific therapy ingredients. Clinical Psychology: Science and Practice, 9, 18-22.

Mohl, P.C., Martinez, D., Ticknor, C. Huang, M., et.al. (1991). Early dropouts from psychotherapy. Journal of Nervous and Mental Disease, 179, 478-481.

*Morlino, M., Di Pietro, G., Tuccillo, R., Galietta, A., Bolzan, M., Senatore, I., Marozzi, M., \& Valoroso, L. (2007). Drop-out rate in eating disorders: Could it be a function of patient-therapist relationship? Eating and Weight Disorders, 12, 64-67.

*Mueller, M., \& Pekarik, G. (2000). Treatment duration prediction: Client accuracy and its relationship to dropout, outcome, and satisfaction. Psychotherapy: Theory, Research, Practice, Training, 37, 117 123.

Norcross, J.C., \& Wampold, B.E. (2011). Evidence-based therapy relationships: Research conclusions and clinical practices, Psychotherapy: Theory, Research, Practice, Training, 48, 98-102.

Norcross, J.C., \& Lambert, M.J. (2011). Psychotherapy relationships that work II, Psychotherapy: Theory, Research, Practice, Training, 48, 4-8.

*Nysaeter, T.E., Nordahl, H.M., \& Havik, O.E. (2010). A preliminary study of the naturalistic course of non-manualized psychotherapy for outpatients with borderline personality disorder: Patient characteristic, attrition and outcome. Nordic Journal of Psychiatry, 64, 87-93.

*O'Brien, A., Fahmy, R., \& Singh, S.W. (2009). Disengagement from mental health services: A literature review. Social Psychiatry Psychiatric Epidemiology, 44, 558-568.

*Ogrodniczuk, J.S., Joyce, A.S., \& Piper, W.E. (2005). Strategies for reducing patient-initiated premature termination of psychotherapy. Harvard Review of Psychiatry, 13, 57-70.

Paivio, S.C., \& Bahr, L.M. (1998). Interpersonal problems, working alliance, and outcome in short-term experiential therapy. Psychotherapy Research, 8, 392-407.

Pekarik, G. (1985a). The effects of employing different termination classification criterion in dropout research. Psychotherapy: Theory, Research, Practice, Training, 22, 86-91.

Pekarik, G. (1985b). Coping with dropouts. Professional Psychology: Research and Practice, 16, 114123.

*Perry, J.P., Bond, M., \& Roy, C. (2007). Predictors of treatment duration and retention in a study of long-term dynamic psychotherapy: Childhood adversity, adult personality, and diagnosis. Journal of Psychiatric Practice, 13, 221-232.

*Pinsker-Aspen, J.H., Stein, M.B., \& Hilsenroth, M.H. (2007). Clinical utility of early memories as a predictor of early therapeutic alliance. Psychotherapy: Theory, Research, Practice, Training, 44, 96-109.

Pollak, J., Mordechai, E., \& Gumpert, P. (1992). Discontinuation from long-term individual psychodynamic psychotherapy. Psychotherapy Research, 2, 224-234. 
Puchner, B., Bauer, S., Horowitz, L.M., \& Kordy, H. (2005). The relationship between interpersonal problems and the helping alliance. Journal of Clinical Psychology, 61, 415-429.

Reis, B.F., \& Brown, L.G. (1999). Reducing psychotherapy dropouts: Maximizing perspective convergence in the psychotherapy dyad. Psychotherapy: Theory, Research, Practice, Training, 36, 123-136.

*Reis, B.F., \& Brown, L.G. (2006). Preventing therapy dropout in the real world: The clinical utility of Videotape preparation and client estimate of treatment duration. Professional Psychology: Research and Practice, 37, 311-316.

*Reitzel, L.R., Stellrecht, N.E., Gordon, K.H., Lima, E.N., Wingate, L.R., Brown, J.S., Wolfe, A.S., Zenoz, L.M., \& Joyner Jr., T.E. (2006). Does time between application and case assignment predict therapy attendance or premature termination in outpatients? Psychological Services, 3, 5160.

Richmond, R. (1992). Discriminating variables among psychotherapy dropouts from a psychological training clinic. Professional Psychology: Research and Practice, 23, 123-130.

Roth, A., \& Fonagy, P. (2004). What works for whom? A critical review of psychotherapy research. London: Guilford Press.

*Ruiz, M.A., Pincus, A.L., Borcovec, T.D., Echemendia, R.J., Castonguay, L.G., \& Ragusea, S.A. (2004). Validity of the Inventory of Interpersonal Problems for predicting treatment outcome: An investigation with the Pennsylvania Practice Research Network. Journal of Personality Assessment, 83, 213-222.

*Samstag, L.W., Muran, J.C., Wachtel, P.L., Slade, A., Safran, J.D., \& Winston, A. (2008). Evaluating negative process: A comparison of working alliance, interpersonal behavior, and narrative coherency among three psychotherapy outcome conditions. American Journal of Psychotherapy, 62, 165-194.

*Shamir, D., Szor, H., \& Melamed, Y. (2010). Dropout, early termination and detachment from a public health psychiatric clinic. Psychiatria Danubina, 22, 46-50.

*Sharf, J., Primavera, L.H., \& Diener, M.J. (2010). Dropout and therapeutic alliance: A meta-analysis of adult individual psychotherapy. Psychotherapy: Theory, Research, Practice, Training, 47, 637645.

*Shoffner, J., Staudt, M., Marcus, S., \& Kapp, S. (2007). Using telephone reminders to increase attendance at psychiatric appointments: Findings of a pilot study in rural Appalachia. Psychiatric Services, 58, 872-875.

Stern, D. (1985). The interpersonal world of the infant: A view from psychoanalysis and development psychology. London: Karnac Books.

Stern, D. (2004). The present moment in psychotherapy and everyday life. London: Norton.

*Thormälen, B., Weinryb, R.M., Norén, K., Vinnars, B., Bågedahl-Strindlund, M., \& Barber, J.P. (2003). Patient factors predicting dropout from supportive-expressive psychotherapy for patients with personality disorders. Psychotherapy Research, 13, 493-509.

*Todd, D.M., Deane, F.P., \& Bragdon, R.A. (2003). Client and therapist reasons for termination: A conceptualization and preliminary validation. Journal of Clinical Psychology, 59, 133-147.

Tryon, G.S. (1999). Counseling dropout relative to client attractiveness, disturbance, and expected number of sessions. Counselling Psychology Quarterly, 12, 285-291. 
*Vasquez, M.J.T. (2007). Cultural difference and the therapeutic alliance: An evidence-based analysis. American Psychologist, 62, 878-885.

Wierzbicki, M., \& Pekarik, G. (1993). A meta-analysis of psychotherapy dropout. Professional Psychology: Research and Practice, 24, 190-195.

*Wilson, M., \& Sperlinger, D. (2004). Dropping out or dropping in? A re-examination of the concept of dropouts using qualitative methodology. Psychoanalytic Psychotherapy, 18, 220-237.

*Young, A.S., Grusky, O., Jordan, D., \& Belin, T.R. (2000). Routine outcome in a public mental health system: The impact of patients who leave care. Psychiatric Services, 51, 85-91. 